\title{
Green Nanoparticles for Mosquito Control
}

\author{
Namita Soni and Soam Prakash \\ Advance and Environmental Parasitology, Vector Control Biotechnology and Biomedical Laboratories, Department of Zoology, \\ Faculty of Science, Dayalbagh Educational Institute, Dayalbagh, Agra 282 110, India \\ Correspondence should be addressed to Soam Prakash; soamprakashdayalbagh@gmail.com
}

Received 18 June 2014; Revised 7 July 2014; Accepted 7 July 2014; Published 27 August 2014

Academic Editor: Xiao-Feng Zhao

Copyright (C) 2014 N. Soni and S. Prakash. This is an open access article distributed under the Creative Commons Attribution License, which permits unrestricted use, distribution, and reproduction in any medium, provided the original work is properly cited.

\begin{abstract}
Here, we have used the green method for synthesis of silver and gold nanoparticles. In the present study the silver (Ag) and gold $(\mathrm{Au})$ nanoparticles (NPs) were synthesized by using the aqueous bark extract of Indian spice dalchini (Cinnamomum zeylanicum) (C. zyelanicum or C. verum J. Presl). Additionally, we have used these synthesized nanoparticles for mosquito control. The larvicidal activity has been tested against the malaria vector Anopheles stephensi and filariasis vector Culex quinquefasciatus. The results were obtained using UV-visible spectrophotometer and the images were recorded with a transmission electron microscope (TEM). The efficacy tests were then performed at different concentrations and varying numbers of hours by probit analysis. The synthesized AgNPs were in spherical shape and average sizes (11.77 nm AgNPs and $46.48 \mathrm{~nm}$ AuNPs). The larvae of An. stephensi were found highly susceptible to the synthesized AgNPs and AuNPs than the Cx. quinquefasciatus. These results suggest that the $C$. zeylanicum synthesized silver and gold nanoparticles have the potential to be used as an ideal ecofriendly approach for the control of mosquito.
\end{abstract}

\section{Introduction}

Cinnamon is a small evergreen tree, which belongs to family Lauraceae. It is the native of Sri Lanka and Southern India. It has antioxidant, antimicrobials, mosquito control, and other properties [1]. Mosquitoes are vectors of many diseases, including malaria, filariasis, dengue, and Japanese encephalitis. Among these kinds of malaria, spread by the bite of female Anopheles mosquito, and filariasis, spread by Culex mosquito, are the two vector borne diseases of the tropical region and are considered major public health concerns.

According to WHO, there were about 219 million cases of malaria in 2010 (with an uncertainty range of 154 million to 289 million) and an estimated 660,000 deaths (with an uncertainty range of 490,000 to 836,000 ). Malaria mortality rate has fallen by more than $25 \%$ globally since 2000 and by $33 \%$ in the WHO African region. Most deaths occur among children living in Africa, where malaria claims the life of a child every minute. Country-level burden estimates available for 2010 show that an estimated $80 \%$ of malaria deaths occur in just 14 countries and about $80 \%$ of cases occur in 17 countries. Together, the Democratic Republic of the Congo and Nigeria account for over $40 \%$ of the total estimated malaria deaths globally [2].

On the other hand, nearly, 1.4 billion people in 73 countries worldwide are threatened by lymphatic filariasis, commonly known as elephantiasis. Over 120 million people are currently infected, with about 40 million disfigured and incapacitated by the disease [3]. Control or eradication of the mosquito population could significantly restrict the spread of disease.

Synthesizing nanoparticles using plants and microorganisms can eliminate this problem by making the nanoparticles more biocompatible. The synthesis of silver nanoparticles from silver precursor using the bark extract and powder of novel Cinnamon zeylanicum has been reported [4]. The potential of nanocrystalline palladium particle production using Cinnamomum zeylanicum (C. zyelanicum or C. verum J. Presl) bark extract has been studied [5].

The silver and gold nanoparticles using A. calamus [6], E. sativa and S. oleracea [7], T. conoides [8], and A. nilotica [9] have been synthesized.

The larvicidal activity of biosynthesized silver nanoparticles using the leaf extracts of $P$. pinnata [10] and L. aspera [11] 
has been tested against the dengue vector Ae. albopictus and Ae. aegypti.

In the present investigation we have synthesized the AgNPs and AuNPs nanoparticles by using the bark extract of C. zeylanicum. Further, the synthesized nanoparticles have also been tested against the larvae of Anopheles stephensi and Culex quinquefasciatus. The C. zeylanicum synthesized AgNPs and AuNPs have the potential to be used as an ideal ecofriendly approach for the control of mosquito.

\section{Materials and Methods}

2.1. Material. The bark of Cinnamomum zeylanicum (C. zyelanicum or C. verum J. Presl) was collected from the local market of Agra, India. The voucher specimen is maintained in our laboratory for future use.

2.2. Extract Preparation. The bark of Cinnamomum zeylanicum (C. zyelanicum or C. verum J. Presl) was washed with distilled water for removing the dust particles. The bark was air-dried and converted into powder and a bark broth was prepared by placing $10 \mathrm{~g}$ of bark powder in a $250 \mathrm{~mL}$ of deionized water. This mixture was boiled at $60^{\circ} \mathrm{C}$, for $5 \mathrm{~min}$, decanted, or filtered through Whatman-1 filter paper.

2.3. Nanoparticles Synthesis. After obtaining the aqueous extract of bark, the filtrates were treated with aqueous $1 \mathrm{mM} \mathrm{AgNO}_{3}$ and $\mathrm{HAuCl}_{4}$ solutions in an Erlenmeyer flask and incubated at room temperature. Formation of AgNPs and AuNPs was indicated by the dark brown and purple coloration of the solutions.

2.4. Characterization of Nanoparticles. Synthesis of AgNPs and AuNPs was confirmed by sampling the reaction mixture at regular intervals, and the absorption maxima were scanned by UV-Vis spectra, at the wavelength of $350-750 \mathrm{~nm}$ in a UV-3600 Shimadzu spectrophotometer at $1 \mathrm{~nm}$ resolution. The micrographs of AgNPs and AuNPs were obtained by TECHNAI $200 \mathrm{Kv}$ TEM (Fei, Electron Optics) transmission electron microscope. For transmission electron microscopy analysis, samples were prepared on carbon coated copper TEM grids.

2.5. Rearing of Mosquito Larvae. The larvae of Cx. quinquefasciatus and An. stephensi were collected from various localities including urban, rural, and semiurban regions of Agra $\left(27^{\circ}, 10^{\prime} \mathrm{N}, 78^{\circ} 05^{\prime} \mathrm{E}\right)$, India. The larvae were reared in deionized water containing glucose and yeast powder. The colonies of $C x$. quinquefasciatus and An. stephensi were maintained in the laboratory at a temperature of $25^{\circ} \mathrm{C}$ with a relative humidity of $75 \pm 5 \%$ and $14 \mathrm{~h}$ of photoperiod. The larvae of Cx. quinquefasciatus and An. stephensi were maintained in separate enamel containers as per the standard method [12].

2.6. Bioassays, Data Management, and Statistical Analysis. AgNPs and AuNPs synthesized from Cinnamomum zeylanicum (C. zyelanicum or C. verum J. Presl) were tested for their

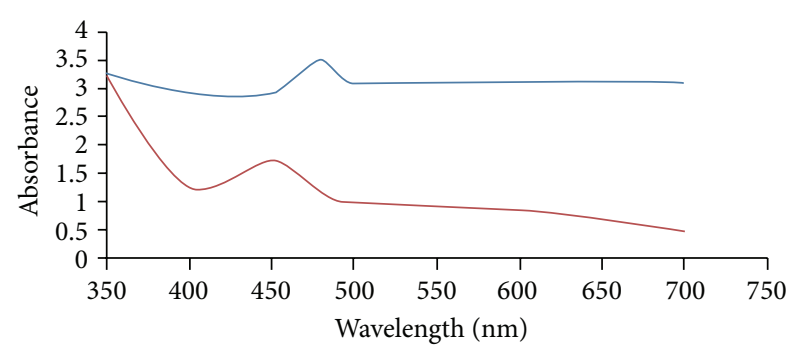

(a)

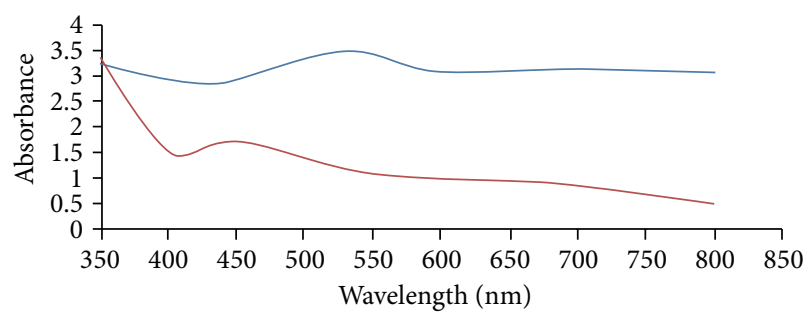

(b)

FIGURE 1: UV-Vis spectra of (a) silver nanoparticles and (b) gold nanoparticles synthesized by using the bark extract of Cinnamomum zeylanicum recorded from reaction medium before (1) and after immersion of $\mathrm{AgNO}_{3}$ (2) after $24 \mathrm{~h}$.

killing activities against the larvae of $C x$. quinquefasciatus and An. stephensi and were assessed by using the standard method [13]. All larvae of Cx. quinquefasciatus and An. stephensi were separated and placed in a container in microbe-free deionized water. After that, different test concentrations of AgNPs and AuNPs in $100 \mathrm{~mL}$ deionized water were prepared in $250 \mathrm{~mL}$ beakers. Bioassays were conducted separately for each instar at five different concentrations of aqueous AgNPs and AuNPs $(2,4,6,8,10 \mathrm{ppm})$. To test the larvicidal activity of our AgNPs and AuNPs, 20 larvae of each stage were separately exposed to $100 \mathrm{~mL}$ of test concentrations. Thereafter, we examined their mortality after different time of treatment during the experimental periods.

The data on the efficacy were subjected to probit analysis [14]. The control mortality was corrected by Abbott's formula $[15]$.

\section{Results}

3.1. Analysis of UV-Vis Spectra. The aqueous extracts of bark of C. zeylanicum (C. zyelanicum or C. verum J. Presl) were light yellow and brown in colour before immersion in $\mathrm{AgNO}_{3}$ and $\mathrm{HAuCl}_{4}$ solutions. The colour of bark aqueous extract changed into dark red and purple colour after immersing in $\mathrm{AgNO}_{3}$ and $\mathrm{HAuCl}_{4}$ solutions after $72 \mathrm{~h}$ of incubation. The change in colour is a signal for the formation of AgNPs and AuNPs. Figures 1(a) and 1(b) show the UV-Vis spectra of synthesized AgNPs and AuNPs using the bark of $C$. zeylanicum (C. zyelanicum or C. verum J. Presl) recorded from reaction medium before (1) and after immersion of $\mathrm{AgNO}_{3}$ and $\mathrm{HAuCl}_{4}$ (2) after $72 \mathrm{~h}$. Absorption spectra of AgNPs 
TABLE 1: Efficacy of silver nanoparticles and gold nanoparticles synthesized by bark extract of Cinnamomum zeylanicum against the larvae of Anopheles stephensi with their LC values, 95\% confidential limits (CL), and $\chi^{2}$ and $r$ values after different time of exposure.

\begin{tabular}{|c|c|c|c|c|c|c|c|}
\hline NPs & Instar & Time & $\mathrm{LC}_{50}(95 \% \mathrm{CL})$ & $\mathrm{LC}_{90}(95 \% \mathrm{CL})$ & $\mathrm{LC}_{99}(95 \% \mathrm{CL})$ & $\chi^{2}$ & $r$ \\
\hline \multirow{4}{*}{ AgNPs } & 1 st & $4 \mathrm{~h}$ & $2(0.86-3.14)$ & $11(9.77-12.23)$ & $12(10.54-13.46)$ & 50.29 & 0.82 \\
\hline & 2nd & $4 \mathrm{~h}$ & $10(8.86-11.14)$ & $15(13.77-16.23)$ & $17(15.54-18.46)$ & 39.43 & 0.95 \\
\hline & $3 \mathrm{rd}$ & $22 \mathrm{~h}$ & $6(4.86-7.16)$ & $11(9.77-12.23)$ & $13(11.54-14.46)$ & 43.83 & 0.95 \\
\hline & 4 th & $22 \mathrm{~h}$ & $10(8.86-11.14)$ & $15(13.83-16.17)$ & $17(15.77-18.77)$ & 37.66 & 0.89 \\
\hline \multirow{4}{*}{ AuNPs } & $1 \mathrm{st}$ & $24 \mathrm{~h}$ & $* *$ & $* *$ & $* *$ & $* *$ & $* *$ \\
\hline & 2nd & $24 \mathrm{~h}$ & $1(0.86-2.14)$ & $8(6.83-9.17)$ & $10.5(9.27-11.73)$ & 61.61 & 0.91 \\
\hline & $3 \mathrm{rd}$ & $72 \mathrm{~h}$ & $1(0.86-2.14)$ & $8(6.83-9.17)$ & $10.5(9.27-11.73)$ & 61.61 & 0.91 \\
\hline & 4 th & $72 \mathrm{~h}$ & $2(0.88-3.12)$ & $10(8.86-11.14)$ & $11(9.87-12.13)$ & 54.93 & 0.89 \\
\hline
\end{tabular}

** $100 \%$ mortality.

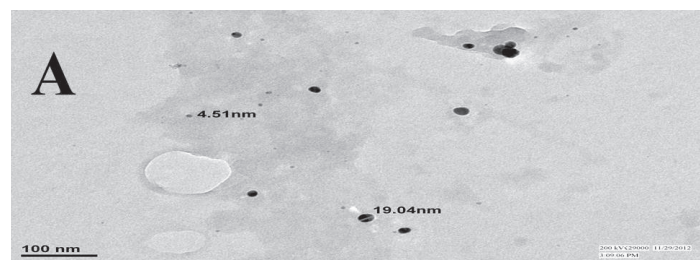

(a)

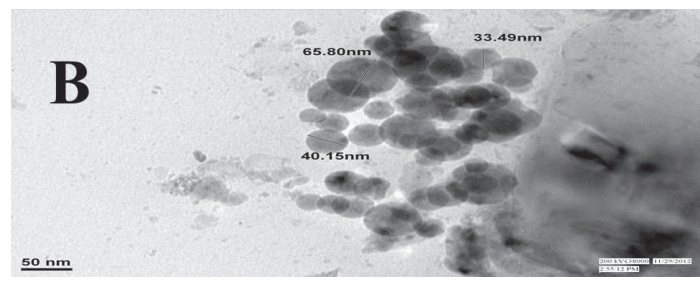

(b)

Figure 2: TEM micrographs of Cinnamomum zeylanicum synthesized (a) silver nanoparticles and (b) gold nanoparticles.

and AuNPs formed in the reaction medium have a broad absorption band centred at $480 \mathrm{~nm}$ and $530 \mathrm{~nm}$ c.a.

3.2. TEM Analysis. Figures 2(a) and 2(b) show the TEM micrographs of synthesized AgNPs and AuNPs. The average size of AgNPs is $11.77 \mathrm{~nm}$ and AuNPs $46.48 \mathrm{~nm}$ and they were spherical-shaped.

3.3. Efficacy of Synthesized AgNPs and AuNPs against An. stephensi Larvae. The efficacy of the synthesized AgNPs and AuNPs was tested against the larvae of An. stephensi. Different concentrations of aqueous AgNPs and AuNPs (2, 4, 6, 8, $10 \mathrm{ppm}$ ) were tested against the larvae of An. stephensi.

The larvae of An. stephensi were found highly susceptible to the synthesized AgNPs. First instar larvae $\left(\mathrm{LC}_{50} 2, \mathrm{LC}_{90} 11\right.$, and $\mathrm{LC}_{99} 12 \mathrm{ppm}$ ), second instar larvae $\left(\mathrm{LC}_{50} 10, \mathrm{LC}_{90} 15\right.$, and $\left.\mathrm{LC}_{99} 17 \mathrm{ppm}\right)$ after $4 \mathrm{~h}$, third instar larvae $\left(\mathrm{LC}_{50} 6, \mathrm{LC}_{90} 11\right.$, and $\left.\mathrm{LC}_{99} 13 \mathrm{ppm}\right)$, and fourth instar larvae $\left(\mathrm{LC}_{50} 10, \mathrm{LC}_{90} 15\right.$, and $\mathrm{LC}_{99} 17 \mathrm{ppm}$ ) after $22 \mathrm{~h}$ of exposure were obtained with their confidence limits and $\chi^{2}$ and $r$ values (Table 1).

The larvae of An. stephensi were found susceptible to the synthesized AuNPs. The first instar larvae have shown

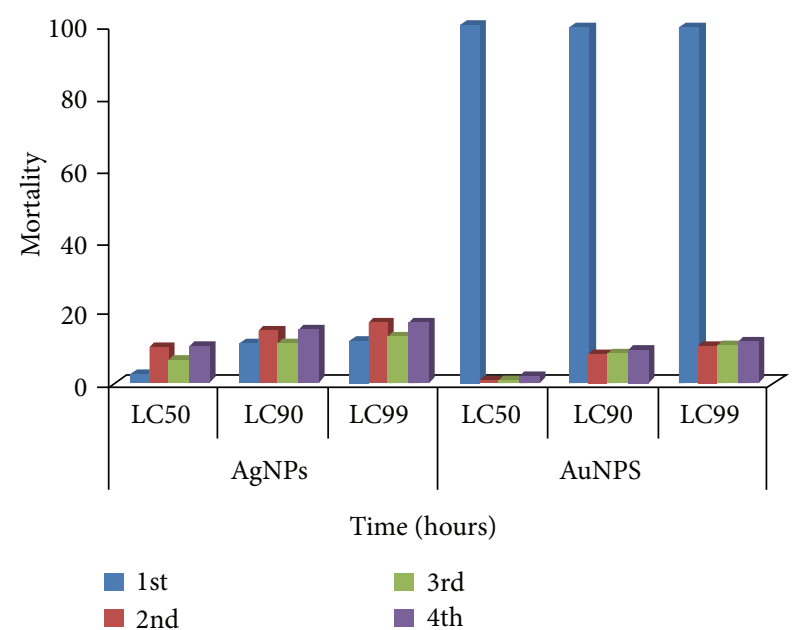

(a)

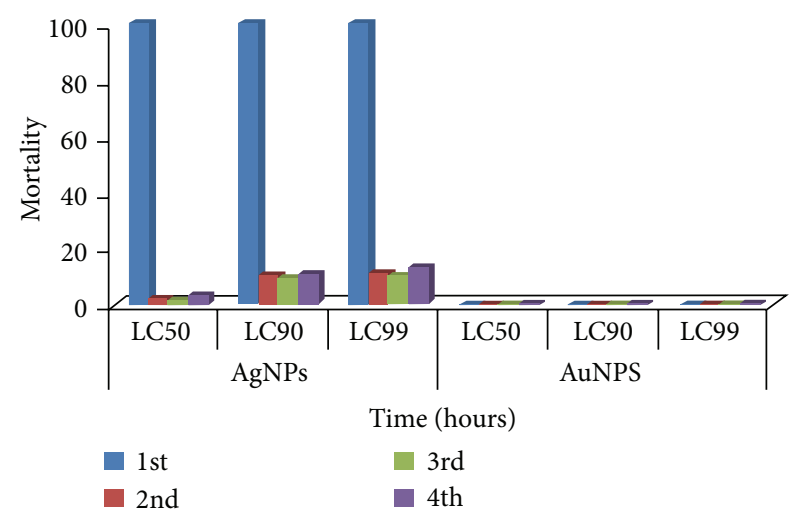

(b)

FIGURE 3: Efficacy of silver and gold nanoparticles against the larvae of Anopheles stephensi at different hours of exposure.

the $100 \%$ mortality after $24 \mathrm{~h}$ of exposure. The second instar larvae $\left(\mathrm{LC}_{50} 1, \mathrm{LC}_{90} 8\right.$, and $\left.\mathrm{LC}_{99} 10.5 \mathrm{ppm}\right)$ after $24 \mathrm{~h}$, third instar larvae ( $\mathrm{LC}_{50} 1, \mathrm{LC}_{90} 8$, and $\left.\mathrm{LC}_{99} 10.5 \mathrm{ppm}\right)$, and fourth instar larvae ( $\mathrm{LC}_{50} 2, \mathrm{LC}_{90} 10$, and $\left.\mathrm{LC}_{99} 11 \mathrm{ppm}\right)$ after $72 \mathrm{~h}$ of exposure were obtained with their confidence limits and $\chi^{2}$ and $r$ values (Table 1, Figure 3(a)). 
TABLE 2: Efficacy of silver nanoparticles and gold nanoparticles synthesized by bark extract of Cinnamomum zeylanicum against the larvae of Culex quinquefasciatus with their LC values, 95\% confidential limits (CL), and $\chi^{2}$ and $r$ values after different time of exposure.

\begin{tabular}{|c|c|c|c|c|c|c|c|}
\hline NPs & Instar & Time & $\mathrm{LC}_{50}(95 \% \mathrm{CL})$ & $\mathrm{LC}_{90}(95 \% \mathrm{CL})$ & $\mathrm{LC}_{99}(95 \% \mathrm{CL})$ & $\chi^{2}$ & $r$ \\
\hline \multirow{4}{*}{ AgNPs } & $1 s t$ & $24 \mathrm{~h}$ & $* *$ & $* *$ & $* *$ & $* *$ & $* *$ \\
\hline & 2nd & $24 \mathrm{~h}$ & $2(0.88-3.12)$ & $10(8.86-11.14)$ & $11(9.87-12.13)$ & 54.93 & 0.89 \\
\hline & $3 \mathrm{rd}$ & $24 \mathrm{~h}$ & $1.5(1.36-2.64)$ & $9(7.77-10.23)$ & $10.5(9.17-11.83)$ & 58.85 & 0.85 \\
\hline & 4 th & $24 \mathrm{~h}$ & $4(2.86-5.14)$ & $11(9.77-12.23)$ & $13(11.54-14.46)$ & 49.41 & 0.87 \\
\hline AuNPs & Larvae & $24 \mathrm{~h}$ & - & - & - & - & - \\
\hline
\end{tabular}

** $100 \%$ mortality.

- no mortality.

3.4. Efficacy of Synthesized AgNPs and AuNPs against Cx. quinquefasciatus Larvae. The efficacy of the synthesized AgNPs and AuNPs was tested against the larvae of $C x$. quinquefasciatus. Different concentrations of aqueous AgNPs and AuNPs (2, 4, 6, 8, 10 ppm) were tested against the larvae of $C x$. quinquefasciatus.

The larvae of Cx. quinquefasciatus were found highly susceptible to the synthesized AgNPs. The first instar larvae have shown the $100 \%$ mortality after $24 \mathrm{~h}$ of exposure. The second instar larvae ( $\mathrm{LC}_{50} 2, \mathrm{LC}_{90} 10$, and $\left.\mathrm{LC}_{99} 11 \mathrm{ppm}\right)$, third instar larvae ( $\mathrm{LC}_{50} 1.5, \mathrm{LC}_{90}$, and $\left.\mathrm{LC}_{99} 10.5 \mathrm{ppm}\right)$, and fourth instar larvae ( $\mathrm{LC}_{50} 4, \mathrm{LC}_{90} 11$, and $\mathrm{LC}_{99} 13 \mathrm{ppm}$ ) after $24 \mathrm{~h}$ of exposure were obtained with their confidence limits and $\chi^{2}$ and $r$ values (Table 2).

The larvae of Cx. quinquefasciatus were found less susceptible to the synthesized AuNPs. No mortality was observed after $24 \mathrm{~h}$ of exposure (Table 2, Figure 3(b)).

\section{Discussion}

In the present investigation we have synthesized the AgNPs and AuNPs by using the bark of C. zeylanicum (C. zyelanicum or C. verum J. Presl). The efficacy of synthesized NPs has been tested against the larvae of malaria vector An. stephensi and filariasis vector $C x$. quinquefasciatus.

An economically viable and "green chemistry" approach for biological synthesis of silver nanoparticles using aqueous leaf extract of $P$. dulce has been reported as larvicidal activity against the $C x$. quinquefasciatus previously [16]. The larvicidal activity of biogenic nanoparticles against filariasis causing Culex mosquito vector has also been evaluated before [17].

Larvicidal activity of silver nanoparticles (AgNPs) using leaf extract of $N$. oleander (Apocynaceae) against the first to the fourth instar larvae and pupae of malaria vector, $A n$. stephensi (Diptera: Culicidae), was carried out in an earlier study [18]. The fabrication, characterization, and mosquito larvicidal bioassay of silver nanoparticles synthesized from aqueous fruit extract of Putranjiva and D. roxburghii were observed [19]. Moreover, the activity of silver nanoparticles (AgNPs) synthesized using M. koenigii plant leaf extract against the first to the fourth instars larvae and pupae of An. stephensi and Ae. aegypti was determined, too [20]. Among these previous studies, the silver nanoparticles were synthesized by using the aqueous extract of leaf and other parts of plant extract and nanoparticles were tested against the first and the fourth instar larvae and pupae of mosquitoes. However, in the present study we have synthesized silver and gold nanoparticles by using aqueous extracts of bark of C. zeylanicum (C. zyelanicum or C. verum J. Presl). These nanoparticles were tested as larvicide against $A n$. stephensi and $C x$. quinquefasciatus.

Recently, the larvicidal activity of silver nanoparticles synthesized by leaf extract of $P$. pinnata has been tested against the larvae of dengue vector Ae. albopictus [10]. Further, the larvicidal potential of silver nanoparticles synthesized from $L$. aspera leaf extract has been tested against the dengue vector Ae. aegypti [11]. However, the larvicidal activity of silver nanoparticles (AgNPs) synthesized using F. elephantum plant leaf extract against late third instar larvae of An. stephensi, Ae. aegypti, and Cx. quinquefasciatus has been determined [21]. Furthermore, activity of aqueous leaf extract and silver nanoparticles (AgNPs) synthesized using $H$. indicum plant leaves against late third instar larvae of Ae. aegypti, An. Stephensi, and Cx. quinquefasciatus has been studied [22]. Larvicidal activity of silver nanoparticles synthesized from aqueous leaf extract of $C$. collinus against the larvae of Ae. aegypti has now been determined [23], while in our study we have synthesized silver nanoparticles by using aqueous extracts of bark of C. zeylanicum (C. zyelanicum or C. verum J. Presl). These nanoparticles were tested as larvicide against An. stephensi and Cx. quinquefasciatus.

The larvicidal activities of synthesized cobalt nanoparticles using the biocontrol agent, B. thuringiensis, have been investigated against the malaria vector An. subpictus and dengue vector, Ae. aegypti [24]. Furthermore, the larvicidal activity of silver nanoparticles synthesized by using $B$. thuringiensis has been revealed against the Ae. aegypti [25], whereas in the present study we have tested the larvicidal activity of silver and gold nanoparticles synthesized by using aqueous extracts of bark of C. zeylanicum (C. zyelanicum or C. verum J. Presl). These nanoparticles were tested as larvicide against An. stephensi and Cx. quinquefasciatus.

Efficacy of fungus mediated silver and gold nanoparticles has been tested against the larvae of An. stephensi, $C x$. Quinquefasciatus, and Ae. aegypti [26-28]. Furthermore, the larvicidal and pupicidal activities of silver and gold nanoparticles synthesized by fungi have also been investigated against An. stephensi, Cx. Quinquefasciatus, and Ae. aegypti [29-31]. Recently the silver nanoparticles have been synthesized by using the leaf and stem of Piper nigrum for their antibacterial activity against agriculture plant pathogens [32]. The silver 
nanoparticles have synthesized by using the leaf of Pimenta dioica [33]. However, in the present study the silver and gold nanoparticles have been synthesized by bark of $C$. zeylanicum against the larvae of An. stephensi and CX. quinquefasciatus.

\section{Conclusion}

In this study we have synthesized the silver and gold nanoparticles by using the bark of Cinnamomum zeylanicum ( $C$. zyelanicum or C. verum J. Presl). The larvicidal activity of the synthesized nanoparticles has been tested against the larvae of malaria vector Anopheles stephensi and filariasis vector Culex quinquefasciatus. The synthesized AgNPs were in spherical shape and average sizes (11.77 nm AgNPs, $46.48 \mathrm{~nm}$ AuNPs). The synthesized nanoparticles were found effective against the larvae of mosquito species. The results suggest that the C. zeylanicum (C. zyelanicum or C. verum J. Presl) synthesized silver and gold nanoparticles have the potential to be used as an ideal ecofriendly approach for the control of mosquito.

\section{Conflict of Interests}

The authors declare that there is no conflict of interests regarding the publication of this paper.

\section{Acknowledgments}

The authors sincerely thank Professor P. S. Satsangi Sahab, Chairman, of Advisory Committee on Education, Dayalbagh Educational Institute, and Professor P. K. Kalra, Director, Dayalbagh Educational Institute, for providing support and encouragements for the work. They also thank to UGC, New Delhi, Major Research Project (39-599/2010), for financial support.

\section{References}

[1] S. S. Lal and P. L. Nayak, "Green synthesis of gold nanoparticles using various extract of plants and species," International Journal of Science Innovations and Discoveries, vol. 2, no. 23, pp. 325-350, 2012.

[2] World Health Organization, "Malaria," 2013, http://www.who .int/mediacentre/factsheets/fs094/en/index.html.

[3] World Health Organization, "Lymphatic filariasis," 2013, http:// www.who.int/mediacentre/factsheets/fs102/en/.

[4] M. Sathishkumar, K. Sneha, S. W. Won, C.-W. Cho, S. Kim, and Y.-S. Yun, "Cinnamon zeylanicum bark extract and powder mediated green synthesis of nano-crystalline silver particles and its bactericidal activity," Colloids and Surfaces B: Biointerfaces, vol. 73, no. 2, pp. 332-338, 2009.

[5] M. Sathishkumar, K. Sneha, I. S. Kwak, J. Mao, S. J. Tripathy, and Y.-S. Yun, "Phyto-crystallization of palladium through reduction process using Cinnamom zeylanicum bark extract," Journal of Hazardous Materials, vol. 171, no. 1-3, pp. 400-404, 2009.

[6] S. Dhanashekaran, S. Karunakaran, R. Amutha, S. Suruthipariyadarshini, and K. Jayalakshmi, "Biosynthesis of silver nanoparticles using Arocus calamus and its antibacterial activity," International Journal of Nanomaterials and Biostructures, vol. 4, no. 1, pp. 16-20, 2014.

[7] I. A. Alaraidh, M. M. Ibrahim, and G. A. El-Gaaly, "Evaluation of green synthesis of Ag nanoparticles using Eruca sativa and Spinacia oleracea leaf extracts and their antimicrobial activity," Iranian Journal of Biotechnology, vol. 12, no. 1, Article ID e12392, 2014.

[8] S. R. Vijayan, P. Santhiyagu, M. Singamuthu, N. K. Ahila, R. Jayaraman, and K. Ehiraj, "Synthesis and characterization of silver and gold nanoparticles using aqueous extract of seaweed, Turbinaria conoides, and their antimicrofouling activity," The Scientific World Journal, vol. 2014, Article ID 938272, 10 pages, 2014.

[9] C. H. Prasad, S. Gangadhara, S. Venkateswarlu, N. V. V. Jyothi, and P. Venkateswarlu, "Green synthesis of silver nanoparticles/ microparticles using extract of Acacia nilotica seeds and their characterization," International Journal of Nanomaterials and Biostructures, vol. 4, no. 1, pp. 1-4, 2014.

[10] B. R. Naik, G. S. Gowreeswari, Y. Singh, R. Satyavathi, R. R. Daravath, and P. R. Reddy, "Bio-synthesis of silver nanoparticles from leaf extract of Pongamia pinnata as an effective larvicide on dengue vector Aedes albopictus (Skuse) (Diptera: Culicidae)," Advances in Entomology, vol. 2, pp. 93-101, 2014.

[11] G. Suganya, S. Karthi, and M. S. Shivakumar, "Larvicidal potential of silver nanoparticles synthesized from Lucas aspera leaf extracts against dengue vector Aedes aegypti," Parasitology Research, vol. 113, no. 5, pp. 1673-1679, 2014.

[12] E. J. Gerberg, D. R. Barnard, and R. A. Ward, "Manual for mosquito rearing and experimental techniques," Journal of American Mosquito Control Association, vol. 5, p. 98, 1994.

[13] World Health Organization, Guidelines for Laboratory and Field Testing of Mosquito Larvicides, WHO/CDS/WHOPES/GCDPP/ 13, 2005.

[14] D. J. Finney, Probit Analysis, Cambridge University Press, Cambridge, UK, 3rd edition, 1971.

[15] W. S. Abbott, "A method of computing the effectiveness of an insecticide," Journal of Economic Entomology, vol. 18, no. 2, pp. 265-267, 1925.

[16] N. Raman, S. Sudharsan, V. Veerakumar, N. Pravin, and K. Vithiya, "Pithecellobium dulce mediated extra-cellular green synthesis of larvicidal silver nanoparticles," Spectrochimica Acta A: Molecular and Biomolecular Spectroscopy, vol. 96, pp. 10311037, 2012.

[17] D. Dhanasekaran and R. Thangaraj, "Evaluation of larvicidal activity of biogenic nanoparticles against filariasis causing Culex mosquito vector," Asian Pacific Journal of Tropical Disease, vol. 3, no. 3, pp. 174-179, 2013.

[18] M. Roni, K. Murugan, C. Panneerselvam, J. Subramaniam, and J.-S. Hwang, "Evaluation of leaf aqueous extract and synthesized silver nanoparticles using Nerium oleander against Anopheles stephensi (Diptera: Culicidae)," Parasitology Research, vol. 112, no. 3, pp. 981-990, 2013.

[19] K. M. Haldar, B. Haldar, and G. Chandra, "Fabrication, characterization and mosquito larvicidal bioassay of silver nanoparticles synthesized from aqueous fruit extract of putranjiva, Drypetes roxburghii (Wall.)," Parasitology Research, vol. 112, no. 4, pp. 1451-1459, 2013.

[20] A. Suganya, K. Murugan, K. Kovendan, P. Mahesh Kumar, and J.-S. Hwang, "Green synthesis of silver nanoparticles using Murraya koenigii leaf extract against Anopheles stephensi and 
Aedes aegypti," Parasitology Research, vol. 112, no. 4, pp. 13851397, 2013.

[21] K. Veerakumar, M. Govindrajan, M. Rajeswary, and U. Muthukumaran, "Low-cost and eco-friendly green synthesis of silver nanoparticles using Feronia elephantum (Rutaceae) against Culex quinquefasciatus, Anopheles stephensi, and Aedes aegypti (Diptera: Culicidae)," Parasitology Research, vol. 113, pp. 17751785, 2014.

[22] K. Veerakumar, M. Govindrajan, M. Rajeswary, and U. Muthukumaran, "Mosquito larvicidal properties of silver nanoparticles synthesized using Heliotropium indicum (Boraginaceae) against Aedes aegypti, Anopheles stephensi, and Culex quinquefasciatus (Diptera: Culicidae)," Parasitology Research, vol. 113, no. 6, pp. 2363-2373, 2014.

[23] G. Ramar, T. Suman, R. Elangomathavan, and A. Jeyasankar, "Larvicidal activity of biologically synthesised silver nanoparticles against dengue vector Aedes Aegypti (Culicidae)," Discovery, vol. 9, pp. 65-68, 2014.

[24] S. Marimuthu, A. A. Rahuman, A. V. Kirthi, T. Santhoshkumar, C. Jayaseelan, and G. Rajakumar, "Eco-friendly microbial route to synthesize cobalt nanoparticles using Bacillus thuringiensis against malaria and dengue vectors," Parasitology Research, vol. 112, no. 12, pp. 4105-4112, 2013.

[25] A. N. Banu, C. Balasubramanian, and P. V. Moorthi, "Biosynthesis of silver nanoparticles using Bacillus thuringiensis against dengue vector, Aedes aegypti (Diptera: Culicidae)," Parasitology Research, vol. 113, no. 1, pp. 311-316, 2014.

[26] N. Soni and S. Prakash, "Efficacy of fungus mediated silver and gold nanoparticles against Aedes aegypti larvae," Parasitology Research, vol. 110, no. 1, pp. 175-184, 2012.

[27] N. Soni and S. Prakash, "Synthesis of gold nanoparticles by the fungus Aspergillus niger and its efficacy against mosquito larvae," Reports in Parasitology, vol. 2, pp. 1-7, 2012.

[28] N. Soni and S. Prakash, "Entomopathogenic fungus generated Nanoparticles for enhancement of efficacy in Culex quinquefasciatus and Anopheles stephensi," Asian Pacific Journal of Tropical Disease, vol. 2, no. 1, pp. S356-S361, 2012.

[29] N. Soni and S. Prakash, "Possible mosquito control by silver nanoparticles synthesized by soil fungus (Aspergillus niger 2587)," Advances in Nanoparticles, vol. 2, pp. 125-132, 2013.

[30] N. Soni and S. Prakash, "Fungus generated novel nanoparticles: a new prospective for mosquito control," International Jornal of Recent Scientific Research, vol. 4, pp. 1481-1487, 2013.

[31] N. Soni and S. Prakash, "Microbial synthesis of spherical nanosilver and nanogold for mosquito control," Annals of Microbiology, vol. 64, no. 3, pp. 1099-1111, 2014.

[32] K. Paulkumar, G. Gnanajobitha, M. Vanaja et al., “Piper nigrum leaf and stem assisted green synthesis of silver nanoparticles and evaluation of its antibacterial activity against agricultural plant pathogens," The Scientific World Journal, vol. 2014, Article ID 829894, 9 pages, 2014.

[33] A. R. Geetha, E. George, A. Srinivasan, and J. Shaik, "Optimization of green synthesis of silver nanoparticles from leaf of Pimenta dioica (Allspice)," The Sciemtific World Journal, vol. 2013, Article ID 362890, 5 pages, 2013. 

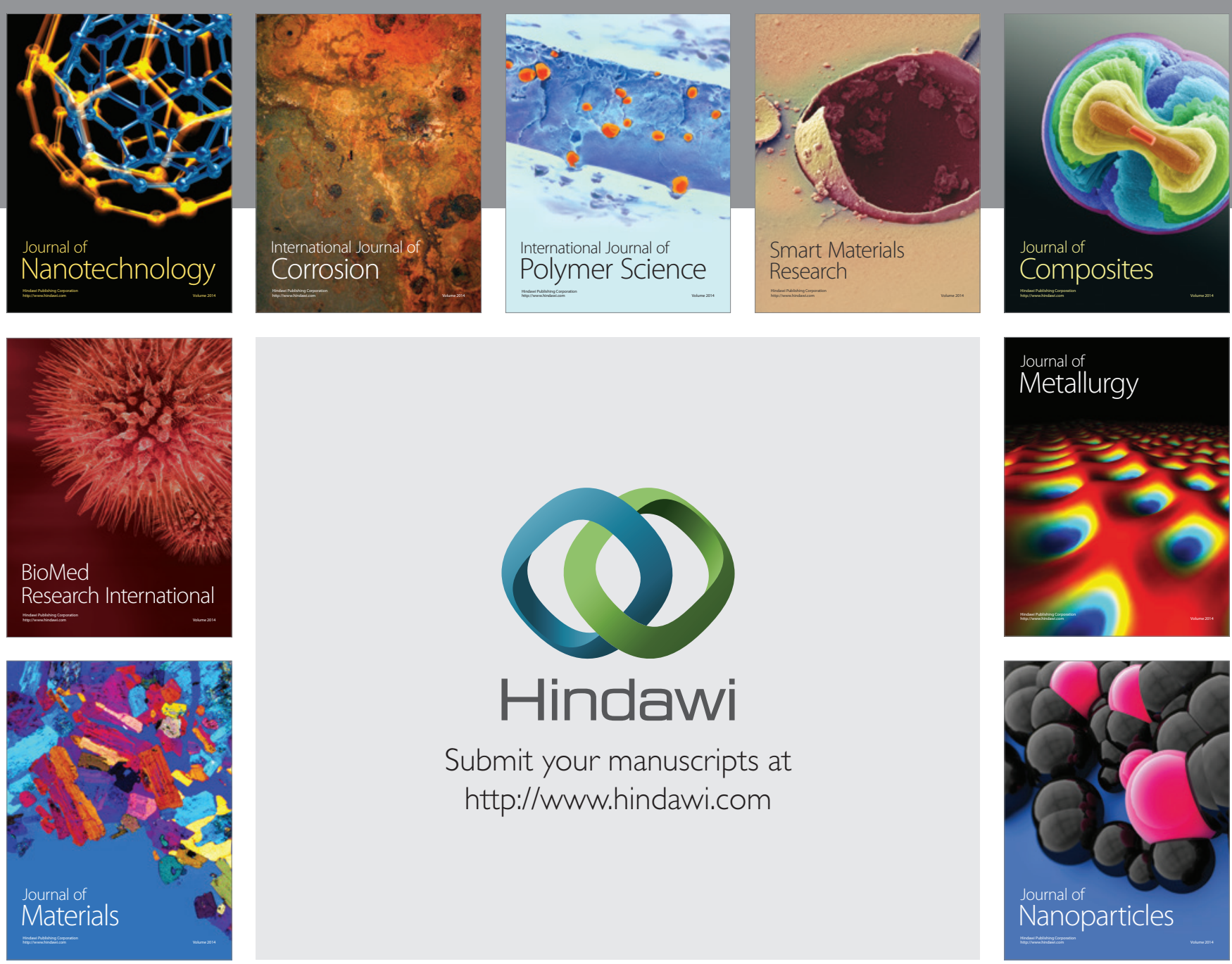

Submit your manuscripts at http://www.hindawi.com
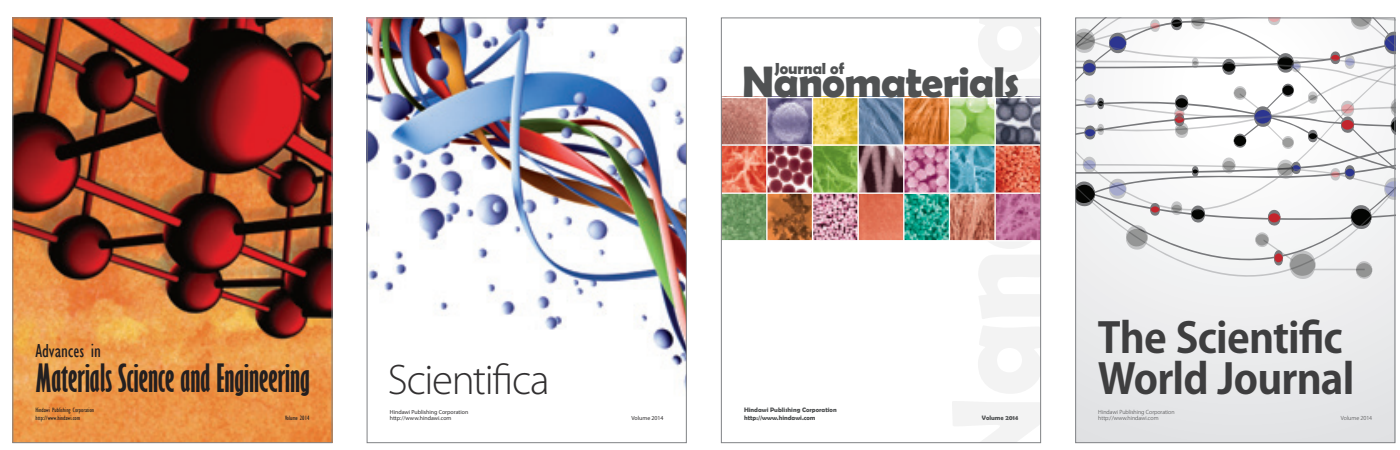

\section{The Scientific World Journal}
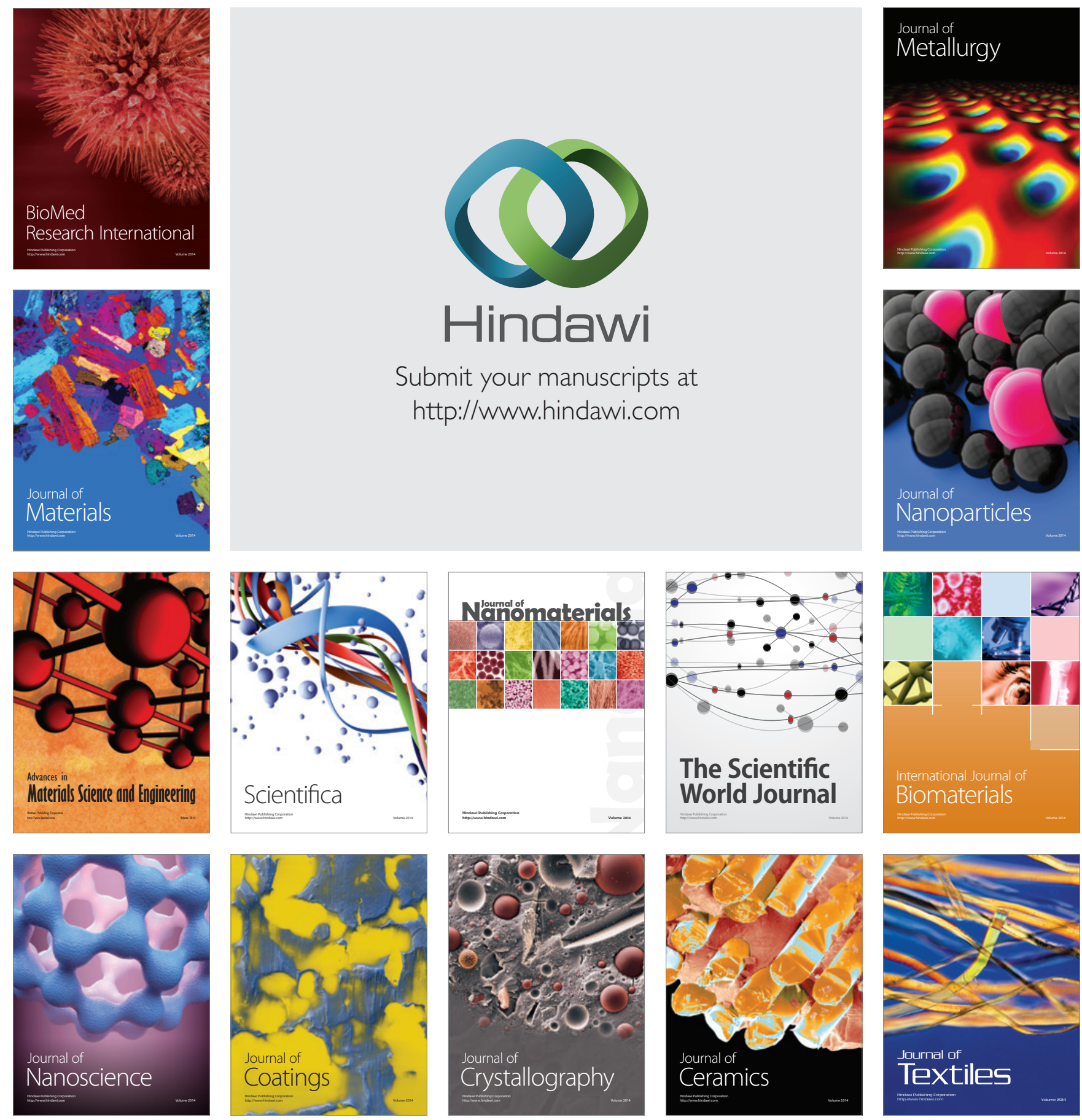